\title{
STRUKTUR DAN SIFAT- SIFAT Q-ALJABAR
}

\author{
Esi Sari, Helmi, Fransiskus Fran
}

\section{INTISARI}

\begin{abstract}
Aljabar abstrak merupakan bagian dari ilmu matematika yang mempelajari struktur aljabar. Pada umumnya struktur aljabar yang dibahas memenuhi sifat asosiatif seperti halnya pada grup, akan tetapi terdapat struktur aljabar yang tidak mensyaratkan sifat asosiatif didalamnya, salah satunya adalah $Q$ aljabar. Suatu himpunan merupakan Q-aljabar apabila himpunan tersebut tak kosong dan memuat konstanta 0 yang dilengkapi dengan operasi biner * serta memenuhi aksioma - aksioma tertentu. Pada penelitian ini mengkaji tentang struktur dan sifat- sifat yang berlaku pada Q-aljabar. Berdasarkan penelitian diperoleh bahwa suatu Q-aljabar yang memenuhi sifat asosiatif merupakan grup. Untuk setiap p-radical merupakan ideal pada $Q$-aljabar, sedangkan tidak seтиa G-bagian merupakan ideal pada $Q$ aljabar. Jika fungsi $f$ merupakan homomorfisma $Q$-aljabar maka $\operatorname{Ker}(f)$ merupakan ideal.
\end{abstract}

Kata Kunci : Q-aljabar,G-bagian, ideal, homomorfisma

\section{PENDAHULUAN}

Matematika merupakan cabang ilmu pengetahuan yang digunakan untuk pengembangan ilmu-ilmu lainnya. Matematika terdiri atas beberapa kelompok ilmu, seperti aljabar, analisis, statistik, dan geometri. Ilmu yang mempelajari penyederhanaan dan pemecahan masalah menggunakan simbol yang menjadi penganti konstanta atau variabel disebut aljabar. Bidang aljabar yang mempelajari aturan manipulasi rumus dan ekspresi yang melibatkan variabel bilangan real atau kompleks disebut aljabar elementer, sementara bagian aljabar yang mempelajari struktur aljabar disebut aljabar abstrak[1].

Teori grup merupakan salah satu bidang kajian aljabar abstrak yang mempelajari struktur himpunan. Suatu himpunan dengan satu operasi biner dinyatakan sebagai grup jika operasi biner pada himpunan tersebut memenuhi sifat asosiatif, adanya elemen identitas dan setiap elemen pada himpunan tersebut memiliki invers [2]. Namun, ada pula struktur aljabar yang mana pada operasinya tidak harus memenuhi sifat assosiatif, seperti Q-aljabar. Suatu himpunan dinyatakan sebagai Q-aljabar apabila himpunan tersebut merupakan himpunan tak kosong yang memuat konstanta 0 dengan suatu operasi biner dan memenuhi aksioma-aksioma tertentu [3]. Suatu Q-aljabar memuat himpunan bagian yang memiliki sifat tertentu di dalamnya seperti G-bagian, p-radical dan ideal. Selain itu di dalam Qaljabar juga terdapat konsep homomorfisma Q-aljabar.

Penelitian ini mengkaji struktur dan sifat-sifat pada Q-aljabar, yaitu membahas definisi dan teorema terkait himpunan bagian pada Q-aljabar yaitu G-bagian, p-radical, ideal. Langkah - langkah pada penelitian, terlebih dahulu menentukan suatu himpunan tak kosong yang memuat konstanta 0 dengan operasi biner $*$, dilanjutkan dengan mengidentifikasi himpunan tersebut dengan aksioma- aksioma yang berlaku pada Q-aljabar. Kemudian menentukan subhimpunan dari Q-aljabar dan mengidentifikasi subhimpunan yang merupakan G-bagian, p-radical dan ideal. Selanjutnya, jika diberikan dua buah himpunan yang merupakan Q-aljabar, didefinisikan suatu pemetaan $f$ suatu homomorfisma Q-aljabar. Lebih lanjut, dengan menggunakan definisi terkait, diperoleh sifat- sifat yang berlaku pada Q-aljabar. 


\section{GRUP}

Grup merupakan salah satu struktur aljabar yang paling umum. Suatu himpunan tak kosong $G$ yang dilengkapi dengan operasi biner $\odot$ disebut grup jika $\odot$ bersifat asosiatif, terdapat elemen identitas di $G$ dan setiap elemen di $G$ memiliki invers di $G$ [2].

Contoh 1 Diberikan $\mathbb{Z}_{4}=\{0,1,2,3\}$ dan didefinisikan operasi $+_{4}$ dari himpunan $\mathbb{Z}_{4}$, maka $\left(\mathbb{Z}_{4},+_{4}\right)$ merupakan grup karena memenuhi aksioma-aksioma pada definisi grup.

Suatu grup $(G, \odot)$ disebut grup abelian jika untuk setiap $a, b \in G$ berlaku $a \odot b=b \odot a$ [4]. Pada suatu grup terdapat himpunan bagian tak kosong dengan operasi biner yang sama dan memenuhi definisi grup, himpunan bagian tersebut disebut subgrup. Lebih lanjut jika diberikan $(G, \odot)$ dan $\left(G^{\prime}, \circ\right)$ adalah sebarang dua grup dan terdapat pemetaan $\varphi: G \rightarrow G^{\prime}$ sedemikian sehingga untuk setiap $a, b \in G$ berlaku $\varphi(a \odot b)=\varphi(a) \circ \varphi(b)$, maka $\varphi$ disebut homomorfisma grup[4].

Contoh 2 Diberikan $(\mathbb{Z},+)$ dan $(2 \mathbb{Z},+)$ merupakan grup. Suatu pemetaan $\varphi:(\mathbb{Z},+) \rightarrow(2 \mathbb{Z},+)$, dengan $\varphi(x)=2 x$ untuk setiap $x \in \mathbb{Z}$ merupakan homomorfisma grup. Hal tersebut karena untuk setiap $x, y \in \mathbb{Z}$ berlaku $\varphi(x+y)=\varphi(x)+\varphi(y)$.

Menurut sifatnya, homomorfisma dibagi menjadi tiga jenis yaitu: homomorfisma yang memenuhi sifat injektif disebut monomorfisma, homomorfisma yang memenuhi sifat surjektif disebut epimorfisma, dan homomorfisma yang bersifat bijektif disebut isomorfisma[5].

Suatu himpunan dikatakan grup jika memenuhi empat aksioma, salah satunya yaitu harus memenuhi sifat asosiatif [2]. Selanjutnya diberikan penjelasan mengenai struktur aljabar lain yang tidak mensyaratkan sifat asosiatif pada operasinya yang disebut Q-aljabar.

\section{Q-ALJABAR}

Suatu Q-aljabar merupakan suatu himpunan tak kosong $X$ yang dilengkapi dengan operasi biner * dan konstanta 0 ditulis $(X, *, 0)$ serta memenuhi beberapa aksioma tertentu. Berikut adalah definisi mengenai Q-aljabar dan contohnya.

Definisi 3 [3] Diberikan $X$ suatu himpunan tak kosong dengan konstanta 0 dan operasi biner $*, X$ disebut $Q$-aljabar jika untuk setiap $x, y, z \in X$ memenuhi aksioma berikut:

(K1) $x * x=0$

(K2) $x * 0=x$

(K3) $(x * y) * z=(x * z) * y$

Berdasarkan Definisi 3, diberikan Contoh 4 pada suatu himpunan yang memuat konstanta 0 serta operasi biner yang memenuhi aksioma pada Q-aljabar.

Contoh 4 Pada Contoh $1,\left(\mathbb{Z}_{4},+_{4}\right)$ merupakan grup. Selanjutnya didefinisikan sebuah operasi $*$ untuk setiap $a, b \in \mathbb{Z}_{4}$ dengan $a * b=a+{ }_{4} b^{-1}$, maka $\left(\mathbb{Z}_{4}, *, 0\right)$ merupakan Q-aljabar karena memenuhi tiga aksioma pada definisi Q-aljabar.

Terdapat keterkaitan antara Q-aljabar dan grup yang dijelaskan pada teorema-teorema berikut.

Teorema 5 [3] Jika $(X, *, 0)$ adalah Q-aljabar, maka $(x *(x * y)) * y=0$, untuk setiap $x, y \in X$.

\section{Bukti:}

Diketahui $x, y \in X$ adalah Q-aljabar dengan operasi biner *, maka berdasarkan K3 dan K2 pada Definisi 3 diperoleh

$$
\begin{aligned}
(x *(x * y)) * y & =(x * y) *(x * y) \\
& =0
\end{aligned}
$$

Teorema 6 [3] Jika $(X, *, 0)$ Q-aljabar memenuhi sifat assosiatif maka $(X, *)$ adalah grup.

\section{Bukti}

Diketahui $(X, *, 0)$ Q-aljabar yang memenuhi sifat asosiatif, berdasarkan Definisi 3 pada K2, $x * 0=$ $x$, maka untuk setiap $x \in X$

$$
\begin{aligned}
0 * x & =(x * x) * x \\
& =x *(x * x) \\
& =x * 0
\end{aligned}
$$




$$
=x
$$

Karena memenuhi sifat asosiatif diperoleh $x * 0=0 * x=x$, maka 0 adalah identitas pada himpunan $X$. Selanjutnya menggunakan $\mathrm{K} 1, x * x=0$, maka untuk setiap $x \in X$ memiliki invers yaitu elemen $x$ sendiri. Berdasarkan penjelasan tersebut yaitu Q-aljabar memenuhi sifat asosiatif, terdapat 0 merupakan identitas pada setiap anggota himpunan $X$ dan untuk setiap $x \in X$ mempunyai invers maka $(X, *)$ merupakan grup.

\section{SUBHIMPUNAN PADA Q-ALJABAR}

Pada Q-aljabar terdapat himpunan bagian yang memiliki sifat - sifat tertentu diantaranya Gbagian, p-radiical dan ideal. Berikut adalah penjelasan mengenai subhimpunan pada Q-aljabar yaitu G-bagian.

Definisi 7 [3] Misalkan $(X, *, 0)$ merupakan Q-aljabar. Untuk sebarang $S$ himpunan tak kosong dengan $S$ himpunan bagian dari $X$, didefinisikan

$$
G(S):=\{x \in S \mid 0 * x=x\}
$$

Jika $S=X$ maka $G(X)$ dikatakan $G$-bagian $X$.

Contoh 8 Berdasarkan Contoh 4 suatu $\left(\mathbb{Z}_{4}, *, 0\right)$ merupakan Q-aljabar. Lebih lanjut menggunakan definisi suatu G-bagian diperoleh bahwa G-bagian $\mathbb{Z}_{4}$ adalah $G\left(\mathbb{Z}_{4}\right)=\{0,2\}$.

Teorema 9 [3] Jika $(X, *, 0)$ adalah Q-aljabar dan $a * b=a * c$, untuk setiap $a, b, c \in X$ maka $0 * b=0 * c$.

\section{Bukti:}

Diketahui untuk setiap $a, b, c \in X$, dengan $a * b=a * c$. Berdasarkan aksioma K2 dan K3 pada Definisi 4, akibatnya

$$
\begin{aligned}
0 * b & =(a * a) * b \\
& =(a * b) * a \\
& =(a * c) * a \\
& =(a * a) * c \\
& =0 * c
\end{aligned}
$$

Jadi untuk setiap $a, b, c \in X$, jika $a * b=a * c$ maka $0 * b=0 * c$.

Akibat 10 [3] Jika X merupakan Q-aljabar maka hukum kanselasi kiri berlaku pada G(X).

Bukti:

Diketahui bahwa himpunan $X$ merupakan Q-aljabar dan

$$
G(X):=\{x \in X \mid 0 * x=x\}
$$

maka untuk setiap $a, b, c \in G(X)$ dengan $a * b=a * c$ dan berdasarkan Teorema 9 dan Definisi 7 berlaku

$$
\begin{aligned}
& \Leftrightarrow 0 * b=0 * c \\
& \Leftrightarrow \quad b=c
\end{aligned}
$$

Jadi berlaku hukum kanselasi kiri pada $G(X)$

Berdasarkan uraian bukti dari Teorema 9 dan Akibat 10, terbukti bahwa pada G-bagian berlaku hukum kanselasi kiri. Selanjutnya diberikan penjelasan subhimpunan lain pada Q-aljabar yaitu $p$ radical.

Definisi 11 [3] Untuk setiap Q-aljabar $(X, *, 0)$, terdapat suatu himpunan

$$
B(X):=\{x \in X \mid 0 * x=0\}
$$

disebut p-radical dari X. Jika $B(X)=\{0\}$, maka X adalah p-semisederhana $Q$-aljabar, sehingga berlaku sifat sebagai berikut:

$$
G(X) \cap B(X)=\{0\} .
$$

Contoh 12 [3] Diberikan himpunan $Y=\{0,1,2,3\}$ dengan operasi * merupakan Q-aljabar melalui hasil operasi pada tabel berikut: 
Tabel 1 Operasi * pada $Y$

\begin{tabular}{c|cccc}
\hline$*$ & 0 & 1 & 2 & 3 \\
\hline 0 & 0 & 0 & 0 & 0 \\
1 & 1 & 0 & 0 & 0 \\
2 & 2 & 0 & 0 & 0 \\
3 & 3 & 3 & 3 & 0 \\
\hline
\end{tabular}

Berdasarkan definisi p-radical maka diperoleh $B(Y)=\{0,1,2,3\}$.

Contoh 13 Berdasarkan Contoh $8, G\left(\mathbb{Z}_{4}\right)=\{0,2\}$ merupakan G-bagian $\mathbb{Z}_{4}$ dan $x \in \mathbb{Z}_{4}$ yang memenuhi Definisi 11 , yaitu untuk $x=0 \in \mathbb{Z}_{4}$ diperoleh $B\left(\mathbb{Z}_{4}\right)=\{0\}$, dan $G\left(\mathbb{Z}_{4}\right) \cap B\left(\mathbb{Z}_{4}\right)=\{0\}$ maka $\mathbb{Z}_{4}$ merupakan $p$-semisederhana Q-aljabar.

Selanjutnya, diberikan penjelasan subhimpunan lain pada Q-aljabar yaitu ideal.

Definisi 14 [3] Diberikan $(X, *, 0)$ suatu Q-aljabar dan terdapat himpunan tak kosong I yang merupakan himpunan bagian dari X. Himpunan I disebut ideal pada $X$ jika untuk setiap $x, y \in X$ berlaku dua kondisi berikut:

(M1) $0 \in I$,

(M2) Jika $x * y \in I$ dan $y \in I$, maka $x \in I$.

Contoh 15 Diberikan $\mathbb{Z}_{6}=\{0,1,2,3,4,5\}$ adalah himpunan bilangan bulat modulo 6, didefinisikan operasi $*$ untuk setiap $x, y \in \mathbb{Z}_{6}$ dengan $x * y=x+{ }_{6} y^{-1}$. Karena memenuhi aksioma K1, K2 dan K3 akibatnya $\left(\mathbb{Z}_{6}, *, 0\right)$ merupakan Q-aljabar. Misalkan terdapat $P=\{0,2,4\}$ merupakan himpunan bagian $\mathbb{Z}_{6}$. Himpunan bagian $P$ merupakan idal pada $\mathbb{Z}_{6}$ karena memenuhi definisi ideal pada Q-aljabar.

Selanjutnya, terdapat keterkaitan antara p-radical dan ideal pada Q-aljabar berdasarkan teorema berikut.

Teorema 16 [3] Misalkan $(X, *, 0)$ adalah $Q$-aljabar, dan $x, y \in X$.

\section{Bukti:}

$$
y \in B(X) \Leftrightarrow(x * y) * x=0 .
$$

Diketahui $(X, *, 0)$ adalah Q-aljabar dan $x, y \in X$

$\Rightarrow$ jika $y \in B(X)$ maka berdasarkan aksioma K3, K1 dan Definisi 12 diperoleh

$$
\begin{aligned}
(x * y) * x & =(x * x) * y \\
& =0 * y \\
& =0 .
\end{aligned}
$$

$\Leftarrow$ jika $(x * y) * x=0$ maka berdasarkan Definisi 3.12, $B(X)=\{y \in X \mid 0 * y=0\}$. Jadi diperoleh $y \in B(X)$

Teorema 17 [3] Misalkan $(X, *, 0)$ suatu $Q$-aljabar, maka $B(X)$ merupakan ideal dari $X$.

\section{Bukti:}

Berdasarkan definisi ideal pada Q-aljabar maka $0 \in B(X)$. Misalkan $x * y \in B(X)$ dan $y \in B(X)$, menggunakan Teorema 16, serta aksioma K3 dan K2 maka diperoleh:

$$
\begin{aligned}
0 & =((x * y) * x) *(x * y) \\
& =((x * y) *(x * y)) * x \\
& =0 * x
\end{aligned}
$$

maka $x \in B(X)$. Jadi $B(X)$ adalah suatu ideal dari $X$.

\section{HOMOMORFISMA Q-ALJABAR}

Suatu Q-aljabar memiliki konsep pemetaan yang disebut homomorfisma Q-aljabar. Penjelasan mengenai homomorfisma pada Q-aljabar terdapat pada definisi berikut.

Definisi 18 [3] Diberikan himpunan $X$ dan $Y$ merupakan $Q$-aljabar. Suatu pemetaan $f: X \rightarrow Y$ disebut homomorfisma $Q$-aljabar jika untuk setiap $x, y \in X$ berlaku

$$
f(x * y)=f(x) * f(y)
$$


dengan $f(x), f(y) \in Y$. Untuk setiap $f$ homomorfisma Q-aljabar, terdapat himpunan $\operatorname{Ker}(f)=\{x \in$ $X \mid f(x)=0\}$ disebut kernel dari fungsi $f$ dan himpunan $\operatorname{Im}(f)=\{f(x) \mid x \in X\}$ disebut image fungsi $f$.

Contoh 19 Diberikan $(\mathbb{Z},-, 0)$ dan $(2 \mathbb{Z},-, 0)$ merupakan Q-aljabar dengan $2 \mathbb{Z}=\{2 k \mid k \in \mathbb{Z}\}$ dan terdapat suatu pemetaan $g:(\mathbb{Z},-, 0) \rightarrow(2 \mathbb{Z},-, 0)$ dengan $g(k)=2 k$, untuk setiap $k \in \mathbb{Z}$. Diambil sebarang $k, l \in \mathbb{Z}$ dengan $g(k)=2 k, g(l)=2 l \in 2 \mathbb{Z}$ maka

$$
\begin{aligned}
g(k-l) & =2(k-l) \\
& =2 k-2 l \\
& =g(k)-g(l)
\end{aligned}
$$

Jadi $g:(\mathbb{Z},-, 0) \rightarrow(2 \mathbb{Z},-, 0)$ merupakan homomorfisma Q-aljabar. Lebih lanjut, berikut adalah kernel dan image dari fungsi $g$.

$$
\begin{aligned}
\operatorname{Ker}(g) & =\{k \in \mathbb{Z} \mid g(k)=0\} \\
& =\{k \in \mathbb{Z} \mid 2 k=0\} \\
& =\{k \in \mathbb{Z} \mid k=0\} \\
& =\{0\} \\
\operatorname{Im}(g) & =\{g(k) \mid k \in \mathbb{Z}\} \\
& =\{2 k \mid k \in \mathbb{Z}\} \\
& =\{\ldots,-4,-2,0,2,4, . .\} \\
& =2 \mathbb{Z}
\end{aligned}
$$

Terdapat beberapa sifat pada homomorfisma Q-aljabar salah satunya keterkaitan homorfisma dengan ideal. Namun, sebelumnya diberikan beberapa teorema berikut:

Teorema 20 [3] Misalkan $f: X \rightarrow Y$ adalah homomorfisma Q-aljabar, maka

(R1) $f(0)=0$

(R2) Jika $x * y=0$, untuk setiap $x, y \in X$ maka $f(x) * f(y)=0$

Bukti:

R1)Diketahui $f: X \rightarrow Y$ homomorfisma Q-aljabar. Diambil $x \in X$, karena $X$ merupakan Q-aljabar berdasarkan $\mathrm{K} 1$, maka $0=x * x$, diperoleh:

$$
\begin{aligned}
f(0) & =f(x * x) \\
& =f(x) * f(x) \\
& =0
\end{aligned}
$$

R2)Diketahui $f: X \rightarrow Y$ merupakan homomorfisma Q-aljabar. Jika $x * y=0, \forall x, y \in X$ maka

$$
\begin{aligned}
f(x) * f(y) & =f(x * y) \\
& =f(0) \\
& =0
\end{aligned}
$$

Teorema 21 [3] Diberikan $(X, *, 0)$ dan $(Y, *, 0)$ merupakan Q-aljabar dan terdapat himpunan $S$ merupakan ideal pada $Y$, maka untuk setiap fungsi $f$ homomorfisma $Q$-aljabar, $f^{-1}(S)$ adalah ideal pada X.

\section{Bukti:}

Diketahui bahwa himpunan $S$ merupakan ideal pada $Y$, dan pemetaan $f: X \rightarrow Y$ merupakan homomorfisma Q-alajabar, maka terdapat himpunan bagian $X$ yaitu himpunan $A$ sehingga $f(A)=S$.

Kemudian karena $f(A)=S$ berlaku sifat kebalikan dari fungsi $f$ diperoleh $A=f^{-1}(S)$, selanjutnya $f^{-1}(S)$ ideal pada $X$.

1.Berdasarkan R1, $\mathrm{f}(0)=0^{\prime} \in \mathrm{S}$. Jadi, $0 \in \mathrm{f}^{-1}(\mathrm{~S})$.

2. Asumsikan $x * y \in f^{-1}(S)$ dan $y \in f^{-1}(S)$, berdasarkan yang diketahui sebelumnya bahwa $S$ merupakan ideal pada $Y$ maka $f(x) * f(y)=f(x * y) \in S$, dan pada Definisi 3.12 diperoleh $f(x) \in S$ maka $x \in f^{-1}(S)$.

Jadi $f^{-1}(S)$ adalah ideal pada $X$. 
Akibat 22 [3] Diketahui $f$ merupakan suatu homomorfisma $Q$-aljabar maka Ker $(f)$ merupakan ideal pada Q-aljabar X.

\section{Bukti:}

Diketahui $X$ merupakan Q-aljabar dan $\operatorname{ker}(f)=\{x \in X \mid f(x)=0\}$. Akan ditunjukkan bahwa $\operatorname{ker}(f)$ merupakan ideal pada $X$.

1. Berdasarkan $\mathrm{R} 1, f(0)=0$ maka $0 \in \operatorname{ker}(f)$.

2. Menggunakan Teorema 21 misalkan untuk $x * y \in \operatorname{ker}(f)$ dan $y \in \operatorname{ker}(f)$ yaitu $f(x * y)=0$ dan $f(y)=0$. Berdasarkan aksioma K2 dan aksioma R1 diperoleh,

$$
\begin{aligned}
f(x) \quad & =f(x * 0) \\
& =f(x) * f(0) \\
& =f(x) * 0 \\
& =f(x) * f(y) \\
& =f(x * y) \\
& =0
\end{aligned}
$$

Jadi, $x \in \operatorname{ker}(f)$. Oleh karena itu, $\operatorname{ker}(f)$ merupakan ideal pada $X$.

\section{KESIMPULAN}

Berdasarkan pembahasan yang telah dipaparkan, maka diperoleh kesimpulan yaitu:

1. Q-aljabar merupakan suatu himpunan tak kosong $X$ dengan operasi biner $*$ dan memuat konstanta 0 sehingga untuk setiap $x, y, z \in X$ memenuhi kondisi sebagai berikut:
a. $x * x=0$
b. $x * 0=x$
c. $(x * y) * z=(x * z) * y$

2. Selanjutnya sifat-sifat Q-aljabar yang diperoleh berdasarkan pembahasan yaitu:

a. Jika $(X, *, 0)$ merupakan Q-aljabar maka untuk setiap $x, y \in X$ berlaku

$$
(x *(x * y)) * y=0 .
$$

b. Jika Q-aljabar $(X, *, 0)$ memenuhi sifat asosiatif maka $(X, *)$ merupakan grup.

c. G-bagian dari Q-aljabar memenuhi hukum kanselasi kiri.

d. Untuk setiap p-radical dari Q-aljabar adalah ideal, akan tetapi tidak dengan G-bagian.

e. Diberikan $f: X \rightarrow Y$ merupakan homomorfisma Q-aljabar. Jika $S$ merupakan ideal pada $Y$ maka $f^{-1}(S)$ ideal pada $X$.

f. Jika suatu $f$ merupakan homomorfisma Q-aljabar maka $\operatorname{Ker}(f)$ merupakan ideal.

\section{DAFTAR PUSTAKA}

[1] Nugroho D, Veronica RB dan Mashuri. Struktur dan Sifat-sifat K-aljabar. UNNES Journal of Mathematics. 2017; 6(1):82-91.

[2] Milne JS. Group Theory. Course Notes; 2013.

[3] Neggers J, Ahn SS. dan Kim HS. On Q-algebras. Article in International Journal of Mathematics and Mathematical Sciences. 2001;749-757.

[4] Judson WT. Abstract Algebra: Theory and Application. Austin State University: Stephen F; 2012.

[5] Durbin JR. Modren Algebra: An Introduction Sixth Edition. The University of Texas at Austin: John Wiley and Sons, Inc; 2009.

ESI SARI

HELMI

FRANSISKUS FRAN
: Jurusan Matematika FMIPA Untan, Pontianak, esisari757@gmail.com

: Jurusan Matematika FMIPA Untan, Pontianak, helmi132205@yahoo.co.id

: Jurusan Matematika FMIPA Untan, Pontianak, fransiskusfran@math.untan.ac.id 